\title{
Neutrophils and Neutrophil Extracellular Traps Drive Necroinflammation in COVID-19
}

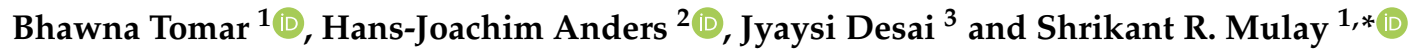 \\ 1 Division of Pharmacology, CSIR-Central Drug Research Institute, Lucknow 226031, India; \\ bhawnatomar415@gmail.com \\ 2 Division of Nephrology, Department of Medicine IV University Hospital LMU, 80336 Munich, Germany; \\ Hans-Joachim.Anders@med.uni-muenchen.de \\ 3 Department of Rheumatology, Leiden University Medical Center, 2333 ZA Leiden, The Netherlands; \\ jyaysidesai@gmail.com \\ * Correspondence: shrikant.mulay@cdri.res.in
}

Received: 6 May 2020; Accepted: 30 May 2020; Published: 2 June 2020

\begin{abstract}
The COVID-19 pandemic is progressing worldwide with an alarming death toll. There is an urgent need for novel therapeutic strategies to combat potentially fatal complications. Distinctive clinical features of severe COVID-19 include acute respiratory distress syndrome, neutrophilia, and cytokine storm, along with severe inflammatory response syndrome or sepsis. Here, we propose the putative role of enhanced neutrophil infiltration and the release of neutrophil extracellular traps, complement activation and vascular thrombosis during necroinflammation in COVID-19. Furthermore, we discuss how neutrophilic inflammation contributes to the higher mortality of COVID-19 in patients with underlying co-morbidities such as diabetes and cardiovascular diseases. This perspective highlights neutrophils as a putative target for the immunopathologic complications of severely ill COVID-19 patients. Development of the novel therapeutic strategies targeting neutrophils may help reduce the overall disease fatality rate of COVID-19.
\end{abstract}

Keywords: SARS-CoV-2; coronavirus; neutrophils; NETs; complement; thrombosis; MERS-CoV; necroinflammation

\section{Introduction}

The novel severe acute respiratory syndrome coronavirus (SARS-CoV)-2 was first discovered in Wuhan, China, and believed to have transmitted from bats to humans [1]. The SARS-CoV-2 has higher human-to-human transmission capabilities compared to the SARS-CoV and Middle East respiratory syndrome coronavirus (MERS-CoV) and has resulted in a pandemic. The World Health Organization has named the disease COVID-19: coronavirus disease-2019; since it was first reported in December 2019. Although SARS-CoV-2 affects lungs at first, it can extend to many organs, including the heart, kidneys, gut, blood vessels, and the brain [2].

The SARS-CoV-2 is closely related to the SARS-CoV since they have $80 \%$ similarity in genome sequence and seven conserved non-structural domains identified by protein sequence analysis $[3,4]$. Moreover, they both have a similar receptor-binding domain, and therefore both use the same cell entry receptor, i.e. angiotensin-converting enzyme II (ACE2) [5]. Subsequently, viral replication in combination with the subsequent antiviral immune response both contribute to the severity of COVID-19, which in some patients involves cytokine storm followed by severe inflammatory response syndrome (SIRS), sepsis, multi-organ failure, and death [6]. However, little is known about the immune pathomechanisms that trigger the cytokine storm during COVID-19. We propose that as part of the first line of the innate immune defense, neutrophils are critical for the exacerbation of the immune 
response, and that neutrophil extracellular traps (NETs)-related necroinflammation plays a central role in the development of the cytokine storm, sepsis and multi-organ failure during COVID-19.

\section{ACE2 and Neutrophils}

ACE2, a homolog of ACE and central negative regulator of the renin-angiotensin system is a type 1 integral membrane glycoprotein monocarboxypeptidase that converts angiotensin-II (AngII) to Ang-(1-7) and is constitutively expressed by the epithelial cells of the lungs, kidney, heart, and intestines on the outer surface [5,7]. Ang-(1-7) is a vasodilator that mediates anti-inflammatory, anti-proliferative, and anti-fibrotic effects through the Mas receptor [8]. Using ACE2-mutant mice, Imai, et al. demonstrated protective functions of ACE2 in acute respiratory distress syndrome (ARDS) [7]. They observed that ACE2 negatively regulates AngII, and thus, increases vascular permeability, lung edema, and the infiltration of neutrophils, partially mediated by the angiotensin 1 receptor (AT1R) [7]. Interestingly, SARS-CoV-infected mice or mice receiving injections of SARS-CoV spike protein showed an aggravated phenotype compared to ACE2-mutant mice, suggesting the contribution of ACE2 beyond being a mere receptor for SARS-CoV [9]. Similar to SARS-CoV, upon binding to ACE2, SARS-CoV-2 enters cells along with ACE2 leading to reduced ACE2 expression on the cell surface [5]. Therefore, the loss of ACE2 might contribute to the severity of ARDS during COVID-19 by increasing AngII- and AT1R-mediated vascular permeability, lung edema, and neutrophils infiltration [10].

How does ACE2 regulate the infiltration of neutrophils mechanistically? Sodhi et al. demonstrated that attenuation of pulmonary ACE2 activity leads to activation of des-Arg9 bradykinin (DABK)/ bradykinin receptor B1 (BKB1R) axis, the release of pro-inflammatory chemokines e.g., C-X-C motif chemokine ligand 5 (CXCL5), macrophage inflammatory protein-2 (MIP2), CXCL1, and tumor necrosis factor (TNF)- $\alpha$ from airway epithelia, increased neutrophil infiltration, and exaggerated endotoxin-induced lung inflammation and injury [11]. The dynamic variation of pulmonary ACE2 was found essential to control neutrophilic inflammation, i.e., a balanced reduction of ACE2 while encountering a bacterial lung infection to recruit inflammatory neutrophils to combat the infection and later its recovery to restrict neutrophil accumulation to alleviate the inflammation by limiting interleukin (IL)-17 signaling by reducing STAT3 pathway activity [12]. Thus, ACE2 prevents the infiltration of neutrophils at the injury or infection site.

\section{SARS-CoV-2, Neutrophils, and Necroinflammation in COVID-19}

An increased neutrophil-to-lymphocyte ratio predicts severe illness in the early stage of SARS-CoV-2 infection, whereas neutrophilia frequently develops in COVID-19 patients in intensive care units [6,13-16]. Being part of the first line of innate immune defense, neutrophils have been thought to have protective roles during bacterial or fungal infections, where they kill bacteria or fungi by phagocytosis as well as NET formation [16]. However, their role in viral infections remains unclear. In murine SARS-CoV infection, neutrophils were dispensable for antibody-mediated clearance of SARS-CoV from pulmonary cells as well as the survival of SARS-CoV-infected mice $[17,18]$. On the other hand, continuous infiltration of neutrophils at the site of infection and their degranulation and release of NETs in response to microbial stimuli to raise an immune response produces exaggerated cytokines and chemokine that might result in the "cytokine storm" and contribute to the ARDS, SIRS and sepsis development during COVID-19 [6,14,19]. Higher levels of interleukin (IL)-1 $\beta$, interferon- $\gamma$, CXCL10, monocyte chemoattractant protein-1, granulocyte colony-stimulating factor, monocyte inhibitory protein-1, and TNF- $\alpha$ were observed in COVID-19 patients requiring ICU admission [6,14]. A lung autopsy from a patient who succumbed to COVID-19 revealed an extensive neutrophil infiltration in pulmonary capillaries with extravasation into the alveolar space displaying acute capillaritis, as well as neutrophilic mucositis of the trachea indicating inflammation to the entire airway [20]. Moreover, SARS-CoV-2 infection of endothelial cells and the accumulation of inflammatory cells induced endothelitis in multiple organs, which may contribute to the systemic 
impaired microcirculatory function during COVID-19 [21] and to the phenomenon of the "happy hypoxia" [22].

The SARS-CoV accessory protein open reading frames SARS3a induced multimodal necrotic cell death in epithelial cells [23]. Interestingly, SARS3a is conserved in SARS-CoV-2 [4], suggesting the engagement of similar pathomechanisms during COVID-19. Cellular necrosis as well as NET formation results in the release of several intracellular danger-associated molecular patterns that activate the pattern recognition receptors on the surrounding immune and non-immune cells resulting in more production of inflammatory cytokines and chemokines [24]. The release of NETs disperses histones, DNA, and granule proteins, such as myeloperoxidase, neutrophil elastase, cathepsin G, and proteinase 3, which results in severe tissue destruction, setting up the auto-amplification loop of necroinflammation [24,25] (Figure 1).

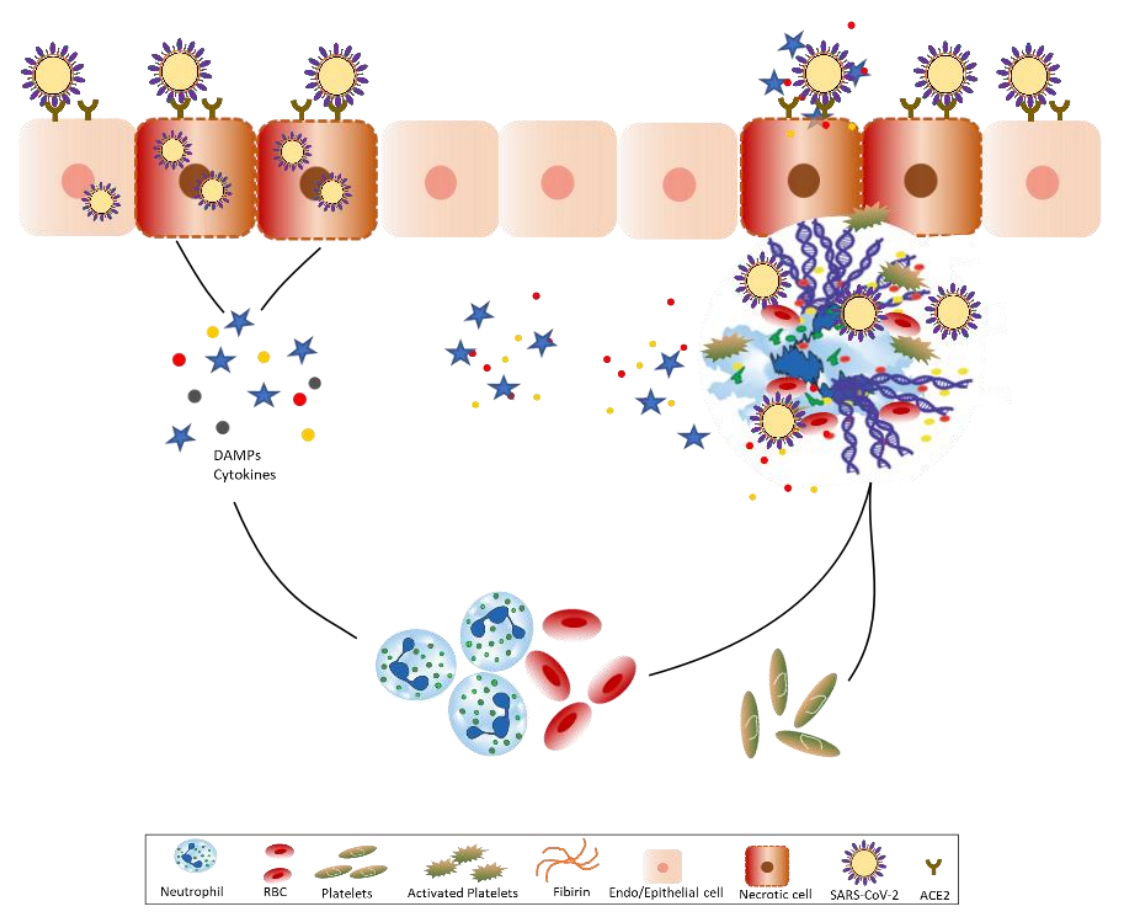

Figure 1. Neutrophils and neutrophil extracellular traps drive necroinflammation in COVID-19. The severe acute respiratory syndrome coronavirus-2 (SARS-CoV-2) binds to ACE2 and enter epithelial as well as endothelial cells along with it leading to reduced ACE2 expression that stimulates neutrophil recruitment. Subsequently, neutrophils undergo degranulation and NET formation releasing intracellular danger-associated molecular patterns, e.g., DNA, histones, neutrophil elastase that activate the pattern recognition receptors on surrounding immune and non-immune cells to induce cytokine secretion. The extracellular DNA released by NETs activates platelets and aggregated NETs provide a scaffold for binding of erythrocytes and activated platelets that promote thrombus formation. The extracellular histones present on NETs induce necrosis in epithelial or endothelial cells leading to the release of associated molecular patterns. This sets up an auto-amplification loop of necroinflammation that aggravate the disease severity during COVID-19. SARS-CoV-2 = severe acute respiratory syndrome coronavirus 2, ACE2 = angiotensin-converting enzyme 2, NET = neutrophil extracellular traps, DAMPs = danger-associated molecular patterns.

NETing neutrophils tend to form larger aggregates called "AggNETs" that drive the formation of thrombi in blood vessels [26]. Interestingly, high incidences of venous thrombosis are reported in COVID-19 [27]. The extracellular DNA released by NETs activates the platelets, and the AggNETs provide a scaffold for binding of the erythrocytes and activated platelets, which further promote the NET formation and set up a vicious cycle propagating thrombus formation [26]. NETs also activate 
the complement system. Myeloperoxidase, cathepsin G, and proteinase 3 activate properdin, factor B, and C3, three components of the alternative pathway required to induce the complement cascade [28]. Activated neutrophils also express properdin, factor B, and C3, suggesting an important role of neutrophils in complement activation. Of note, activation of the complement system has been reported in the severe COVID-19 patients [27]. Together, neutrophils infiltration and NETs formation drive necroinflammation during coronavirus infections (Table 1).

Table 1. Evidence for neutrophil-mediated necroinflammation in coronavirus infections.

\begin{tabular}{|c|c|c|}
\hline Virus & Evidence for Involvement of Neutrophils & Reference \\
\hline \multirow{4}{*}{ SARS-CoV-2 } & $\begin{array}{l}\text { High levels of markers of NETs, e.g., cell free-DNA, myeloperoxidase-DNA, } \\
\text { and citrullinated histone } 3 \text { in sera from severely ill patients }\end{array}$ & [19] \\
\hline & High neutrophil-to-lymphocyte ratio cause ARDS in patients & {$[13,15,29]$} \\
\hline & Neutrophil infiltration in pulmonary capillaries with extravasation into the alveolar space & [20] \\
\hline & High neutrophil-to-lymphocyte ratio and D-dimer levels in patients & [30] \\
\hline \multirow{5}{*}{ SARS-CoV } & C3 mediated neutrophil recruitment during disease progression in mice & [31] \\
\hline & Neutrophils infiltration in lungs during the late phase of infection in mice & [32] \\
\hline & Neutrophils count correlate with the cytokine storm in patients & [33] \\
\hline & Higher levels of neutrophil chemokine IL- 8 found in patients & [34] \\
\hline & Neutrophilia is associated with the severity of disease in patients & [35] \\
\hline \multirow{3}{*}{ MERS-CoV } & Neutrophil-mediated innate inflammatory response in human DPP4 knock-in mice & [36] \\
\hline & $\begin{array}{l}\text { Increased neutrophils contribute to leukocytosis, an indicator of disease severity and } \\
\text { fatality in patients }\end{array}$ & [37] \\
\hline & $\begin{array}{l}\text { Increased release of ROS caused extensive pulmonary lesions and increased the disease } \\
\text { severity in marmosets }\end{array}$ & [38] \\
\hline
\end{tabular}

SARS-CoV = severe acute respiratory syndrome coronavirus, MERS-CoV = Middle East respiratory syndrome coronavirus, $\mathrm{NET}=$ neutrophil extracellular trap, ARDS = acute respiratory distress syndrome, $\mathrm{C} 3=$ complement factor $3, \mathrm{ROS}=$ reactive oxygen species.

\section{Diabetes, SARS-CoV-2, and Neutrophils}

Many prevalent co-morbidities increase the severity and mortality of COVID-19 [14,27,39-41]. One of the most distinctive co-morbidities is diabetes mellitus [6]. Out of 1099 cases reported by Guan et al., $16.2 \%$ of patients with severe disease had a higher prevalence of diabetes compared to $5.7 \%$ of patients with the non-severe disease [14]. Case fatality was higher in COVID patients with diabetes [42]. This may be attributed to the dysfunctional innate immunity, as well as the exaggerated pro-inflammatory cytokine response in patients with diabetes [43]. Furthermore, higher glucose levels glycosylate and shed ACE2 [44] may contribute to the severity of ARDS during COVID-19 by increasing vascular permeability, edema, and neutrophils infiltration in DM patients. On the other hand, it was believed that patients with diabetes treated with ACE inhibitors and angiotensin-receptor blockers may develop increased ACE2 expression, which could further facilitate the cell entry of SARS-CoV-2 and aggravate the infection [40]. However, a recent study reported no association with the likelihood of COVID-19 positive test or severity of COVID-19 with renin-angiotensin system inhibitors [45]. Hyperglycemia in diabetes primes neutrophils to release NETs that might further contribute to the cytokine storm, SIRS, and sepsis in COVID-19 [43]. Besides, sugar-activated neutrophils produce S100 Calcium-binding proteins A8/A9 (S100A8/A9) that increased the production of thrombopoietin in the liver and subsequent thrombocytosis [46], which might contribute to thrombus formation in COVID-19. Th17-associated cytokine production promoted disease-predictive inflammation in DM [47]. Interestingly, a higher number of CCR6+ TH17 cells were found in the peripheral blood of COVID-19 patients, suggesting critical involvement of TH17 response [48]. Together, neutrophil-mediated cytokine storm leads to sepsis and subsequent multi-organ failure to aggravate the severity of COVID-19 disease. 


\section{Cardiovascular Diseases, SARS-CoV-2, and Neutrophils}

Cardiovascular diseases, including coronary heart disease, cardiomyopathy, arrhythmias, myocardial injury, and hypertension are other distinctive co-morbidities of COVID-19 that have higher overall mortality rates [14,42,49]. Especially, the extent of myocardial injury correlated with cardiac dysfunction, arrhythmias, and fatal outcome of COVID-19 [49]. ACE2 exerts vasodilatory effects through Ang-(1-7) and the Mas receptor [8]. Therefore downregulation of ACE2 upon SARS-CoV-2 cell entry induces vasoconstriction and subsequent hypertension. Subsequent ACE2-mediated neutrophil infiltration, as well as NET formation, might be responsible for the exaggerated inflammatory response, which in turn contributes to the development of cardiovascular diseases, e.g., thrombosis, atherosclerosis, and endothelial injury, etc. One in five hospitalized COVID-19 patients showed increased troponin, brain natriuretic peptide, lymphopenia, and inflammation markers, such as c-reactive protein, IL- $1 \beta$, and IL- 6 in the early course of the disease suggesting cardiac injury $[49,50]$. Recently, NET-related endothelial cell injury was reported to contribute to vascular pathology in pulmonary hypertension [39]. Moreover, IL-1 $\beta$ promoted the thrombus formation via NET-associated tissue factor during atheroembolic events during cardiovascular diseases [51,52]. Furthermore, increased neutrophil elastase activity was reported to contribute to obesity, insulin resistance, and related inflammation [53]. Interestingly, the presence of obesity in metabolic associated fatty liver disease increased the severity of COVID-19 six-fold [41]. All these reports indicate the involvement of neutrophils and related necroinflammation in the pathology and severity of COVID-19.

\section{Summary and Perspectives}

To summarize, neutrophils play a central role in the immunopathology of COVID-19. SARS-CoV-2 infection, as well as downregulation of ACE2 upon the cell entry of SARS-CoV-2 triggers neutrophil infiltration in the lungs. Necrotic cell death of alveolar epithelial cells, as well as NET formation, releases damage-associated molecular patterns and alarmins in the surrounding extracellular space, which induce production of pro-inflammatory cytokines and vice versa, setting up a loop of necroinflammation that is responsible for the cytokine storm and sepsis. NETting neutrophils cause endothelial injury and necroinflammation via complement activation, as well as promote the venous thrombus formation during COVID-19. Underlying co-morbidities in COVID-19 patients, e.g., diabetes and cardiovascular diseases enhance the neutrophilic inflammation and thereby severity of COVID-19. Therefore, the development of novel therapeutic strategies targeted at neutrophils, e.g., inhibitors of neutrophil recruitment or NET formation may help reduce the overall disease mortality rate of COVID-19.

Author Contributions: S.R.M. conceived the idea. B.T., H.-J.A., J.D., S.R.M. wrote the manuscript. All authors have read and agreed to the published version of the manuscript.

Funding: This research was funded by grants from the Department of Biotechnology, Government of India (BT/RLF/Re-entry/01/2017) and Council of Scientific and Industrial Research (CSIR), India to S.R.M. and the Deutsche Forschungsgemeinschaft (AN372/14-3, 23-1, and 24-1) to H.-J.A.

Acknowledgments: This manuscript has CDRI communication number 10074.

Conflicts of Interest: The authors declare no conflict of interest.

\section{References}

1. Zhou, P.; Yang, X.L.; Wang, X.G.; Hu, B.; Zhang, L.; Zhang, W.; Si, H.R.; Zhu, Y.; Li, B.; Huang, C.L.; et al. A pneumonia outbreak associated with a new coronavirus of probable bat origin. Nature 2020, 579, 270-273. [CrossRef] [PubMed]

2. Wadman, M.; Couzin-Frankel, J.; Kaiser, J.; Matacic, C. A rampage through the body. Science 2020, 368, 356-360. [PubMed] 
3. Lu, R.; Zhao, X.; Li, J.; Niu, P.; Yang, B.; Wu, H.; Wang, W.; Song, H.; Huang, B.; Zhu, N.; et al. Genomic characterisation and epidemiology of 2019 novel coronavirus: Implications for virus origins and receptor binding. Lancet 2020, 395, 565-574. [CrossRef]

4. Wrapp, D.; Wang, N.; Corbett, K.S.; Goldsmith, J.A.; Hsieh, C.L.; Abiona, O.; Graham, B.S.; McLellan, J.S. Cryo-EM structure of the 2019-nCoV spike in the prefusion conformation. Science 2020, 367, 1260-1263. [CrossRef] [PubMed]

5. Hoffmann, M.; Kleine-Weber, H.; Schroeder, S.; Kruger, N.; Herrler, T.; Erichsen, S.; Schiergens, T.S.; Herrler, G.; Wu, N.H.; Nitsche, A.; et al. SARS-CoV-2 Cell Entry Depends on ACE2 and TMPRSS2 and Is Blocked by a Clinically Proven Protease Inhibitor. Cell 2020, 181, 271-280.e278. [CrossRef] [PubMed]

6. Huang, C.; Wang, Y.; Li, X.; Ren, L.; Zhao, J.; Hu, Y.; Zhang, L.; Fan, G.; Xu, J.; Gu, X.; et al. Clinical features of patients infected with 2019 novel coronavirus in Wuhan, China. Lancet 2020, 395, 497-506. [CrossRef]

7. Imai, Y.; Kuba, K.; Rao, S.; Huan, Y.; Guo, F.; Guan, B.; Yang, P.; Sarao, R.; Wada, T.; Leong-Poi, H.; et al. Angiotensin-converting enzyme 2 protects from severe acute lung failure. Nature 2005, 436, 112-116. [CrossRef]

8. Xu, J.; Fan, J.; Wu, F.; Huang, Q.; Guo, M.; Lv, Z.; Han, J.; Duan, L.; Hu, G.; Chen, L.; et al. The ACE2/Angiotensin-(1-7)/Mas Receptor Axis: Pleiotropic Roles in Cancer. Front. Physiol. 2017, 8, 276. [CrossRef]

9. Kuba, K.; Imai, Y.; Rao, S.; Gao, H.; Guo, F.; Guan, B.; Huan, Y.; Yang, P.; Zhang, Y.; Deng, W.; et al. A crucial role of angiotensin converting enzyme 2 (ACE2) in SARS coronavirus-induced lung injury. Nat. Med. 2005, 11, 875-879. [CrossRef]

10. Eguchi, S.; Kawai, T.; Scalia, R.; Rizzo, V. Understanding Angiotensin II Type 1 Receptor Signaling in Vascular Pathophysiology. Hypertension 2018, 71, 804-810. [CrossRef]

11. Sodhi, C.P.; Wohlford-Lenane, C.; Yamaguchi, Y.; Prindle, T.; Fulton, W.B.; Wang, S.; McCray, P.B., Jr.; Chappell, M.; Hackam, D.J.; Jia, H. Attenuation of pulmonary ACE2 activity impairs inactivation of des-Arg(9) bradykinin/BKB1R axis and facilitates LPS-induced neutrophil infiltration. Am. J. Physiol. Lung Cell. Mol. Physiol. 2018, 314, L17-L31. [CrossRef] [PubMed]

12. Sodhi, C.P.; Nguyen, J.; Yamaguchi, Y.; Werts, A.D.; Lu, P.; Ladd, M.R.; Fulton, W.B.; Kovler, M.L.; Wang, S.; Prindle, T., Jr.; et al. A Dynamic Variation of Pulmonary ACE2 Is Required to Modulate Neutrophilic Inflammation in Response to Pseudomonas aeruginosa Lung Infection in Mice. J. Immunol. 2019, 203, 3000-3012. [CrossRef] [PubMed]

13. Liu, Y.; Du, X.; Chen, J.; Jin, Y.; Peng, L.; Wang, H.H.X.; Luo, M.; Chen, L.; Zhao, Y. Neutrophil-to-lymphocyte ratio as an independent risk factor for mortality in hospitalized patients with COVID-19. J. Infect. 2020. [CrossRef] [PubMed]

14. Guan, W.J.; Ni, Z.Y.; Hu, Y.; Liang, W.H.; Ou, C.Q.; He, J.X.; Liu, L.; Shan, H.; Lei, C.L.; Hui, D.S.C.; et al. Clinical Characteristics of Coronavirus Disease 2019 in China. N. Engl. J. Med. 2020, 382, 1708-1720. [CrossRef]

15. Lagunas-Rangel, F.A. Neutrophil-to-lymphocyte ratio and lymphocyte-to-C-reactive protein ratio in patients with severe coronavirus disease 2019 (COVID-19): A meta-analysis. J. Med. Virol. 2020. [CrossRef]

16. Németh, T.; Sperandio, M.; Mócsai, A. Neutrophils as emerging therapeutic targets. Nat. Rev. Drug Discov. 2020, 19, 253-275. [CrossRef]

17. Yasui, F.; Kohara, M.; Kitabatake, M.; Nishiwaki, T.; Fujii, H.; Tateno, C.; Yoneda, M.; Morita, K.; Matsushima, K.; Koyasu, S.; et al. Phagocytic cells contribute to the antibody-mediated elimination of pulmonary-infected SARS coronavirus. Virology 2014, 454-455, 157-168. [CrossRef]

18. Channappanavar, R.; Fehr, A.R.; Vijay, R.; Mack, M.; Zhao, J.; Meyerholz, D.K.; Perlman, S. Dysregulated Type I Interferon and Inflammatory Monocyte-Macrophage Responses Cause Lethal Pneumonia in SARS-CoV-Infected Mice. Cell Host Microbe 2016, 19, 181-193. [CrossRef]

19. Zuo, Y.; Yalavarthi, S.; Shi, H.; Gockman, K.; Zuo, M.; Madison, J.A.; Blair, C.N.; Weber, A.; Barnes, B.J.; Egeblad, M.; et al. Neutrophil extracellular traps in COVID-19. JCI Insight 2020. [CrossRef]

20. Barnes, B.J.; Adrover, J.M.; Baxter-Stoltzfus, A.; Borczuk, A.; Cools-Lartigue, J.; Crawford, J.M.; Daßler-Plenker, J.; Guerci, P.; Huynh, C.; Knight, J.S.; et al. Targeting potential drivers of COVID-19: Neutrophil extracellular traps. J. Exp. Med. 2020, 217, e20200652. [CrossRef] 
21. Varga, Z.; Flammer, A.J.; Steiger, P.; Haberecker, M.; Andermatt, R.; Zinkernagel, A.S.; Mehra, M.R.; Schuepbach, R.A.; Ruschitzka, F.; Moch, H. Endothelial cell infection and endotheliitis in COVID-19. Lancet 2020, 395, 1417-1418. [CrossRef]

22. Couzin-Frankel, J. The mystery of the pandemic's 'happy hypoxia'. Science 2020, 368, 455-456. [CrossRef]

23. Yue, Y.; Nabar, N.R.; Shi, C.S.; Kamenyeva, O.; Xiao, X.; Hwang, I.Y.; Wang, M.; Kehrl, J.H. SARS-Coronavirus Open Reading Frame-3a drives multimodal necrotic cell death. Cell Death Dis. 2018, 9, 904. [CrossRef]

24. Linkermann, A.; Stockwell, B.R.; Krautwald, S.; Anders, H.J. Regulated cell death and inflammation: An auto-amplification loop causes organ failure. Nat. Rev. Immunol. 2014, 14, 759-767. [CrossRef]

25. Mulay, S.R.; Linkermann, A.; Anders, H.J. Necroinflammation in Kidney Disease. J. Am. Soc. Nephrol. 2016, 27, 27-39. [CrossRef]

26. Nakazawa, D.; Desai, J.; Steiger, S.; Müller, S.; Devarapu, S.K.; Mulay, S.R.; Iwakura, T.; Anders, H.J. Activated platelets induce MLKL-driven neutrophil necroptosis and release of neutrophil extracellular traps in venous thrombosis. Cell Death Discov. 2018, 4, 6. [CrossRef]

27. Llitjos, J.F.; Leclerc, M.; Chochois, C.; Monsallier, J.M.; Ramakers, M.; Auvray, M.; Merouani, K. High incidence of venous thromboembolic events in anticoagulated severe COVID-19 patients. J. Thromb. Haemost. 2020. [CrossRef]

28. de Bont, C.M.; Boelens, W.C.; Pruijn, G.J.M. NETosis, complement, and coagulation: A triangular relationship. Cell. Mol. Immunol. 2019, 16, 19-27. [CrossRef]

29. Liu, J.; Liu, Y.; Xiang, P.; Pu, L.; Xiong, H.; Li, C.; Zhang, M.; Tan, J.; Xu, Y.; Song, R.; et al. Neutrophil-to-lymphocyte ratio predicts critical illness patients with 2019 coronavirus disease in the early stage. J. Transl. Med. 2020, 18, 206. [CrossRef]

30. Fu, J.; Kong, J.; Wang, W.; Wu, M.; Yao, L.; Wang, Z.; Jin, J.; Wu, D.; Yu, X. The clinical implication of dynamic neutrophil to lymphocyte ratio and D-dimer in COVID-19: A retrospective study in Suzhou China. Thromb. Res. 2020, 192, 3-8. [CrossRef]

31. Gralinski, L.E.; Sheahan, T.P.; Morrison, T.E.; Menachery, V.D.; Jensen, K.; Leist, S.R.; Whitmore, A.; Heise, M.T.; Baric, R.S. Complement Activation Contributes to Severe Acute Respiratory Syndrome Coronavirus Pathogenesis. mBio 2018, 9, e01753-18. [CrossRef] [PubMed]

32. Chen, J.; Lau, Y.F.; Lamirande, E.W.; Paddock, C.D.; Bartlett, J.H.; Zaki, S.R.; Subbarao, K. Cellular immune responses to severe acute respiratory syndrome coronavirus (SARS-CoV) infection in senescent BALB/c mice: CD4+ T cells are important in control of SARS-CoV infection. J. Virol. 2010, 84, 1289-1301. [CrossRef] [PubMed]

33. Huang, K.J.; Su, I.J.; Theron, M.; Wu, Y.C.; Lai, S.K.; Liu, C.C.; Lei, H.Y. An interferon-gamma-related cytokine storm in SARS patients. J. Med. Virol. 2005, 75, 185-194. [CrossRef] [PubMed]

34. Wong, C.K.; Lam, C.W.; Wu, A.K.; Ip, W.K.; Lee, N.L.; Chan, I.H.; Lit, L.C.; Hui, D.S.; Chan, M.H.; Chung, S.S.; et al. Plasma inflammatory cytokines and chemokines in severe acute respiratory syndrome. Clin. Exp. Immunol. 2004, 136, 95-103. [CrossRef]

35. Wong, R.S.; Wu, A.; To, K.F.; Lee, N.; Lam, C.W.; Wong, C.K.; Chan, P.K.; Ng, M.H.; Yu, L.M.; Hui, D.S.; et al. Haematological manifestations in patients with severe acute respiratory syndrome: Retrospective analysis. BMJ 2003, 326, 1358-1362. [CrossRef]

36. Li, K.; Wohlford-Lenane, C.L.; Channappanavar, R.; Park, J.E.; Earnest, J.T.; Bair, T.B.; Bates, A.M.; Brogden, K.A.; Flaherty, H.A.; Gallagher, T.; et al. Mouse-adapted MERS coronavirus causes lethal lung disease in human DPP4 knockin mice. Proc. Natl. Acad. Sci. USA 2017, 114, 3119-3128. [CrossRef]

37. Min, C.K.; Cheon, S.; Ha, N.Y.; Sohn, K.M.; Kim, Y.; Aigerim, A.; Shin, H.M.; Choi, J.Y.; Inn, K.S.; Kim, J.H.; et al. Comparative and kinetic analysis of viral shedding and immunological responses in MERS patients representing a broad spectrum of disease severity. Sci. Rep. 2016, 6, 25359. [CrossRef]

38. Baseler, L.J.; Falzarano, D.; Scott, D.P.; Rosenke, R.; Thomas, T.; Munster, V.J.; Feldmann, H.; de Wit, E. An Acute Immune Response to Middle East Respiratory Syndrome Coronavirus Replication Contributes to Viral Pathogenicity. Am. J. Pathol. 2016, 186, 630-638. [CrossRef]

39. Aldabbous, L.; Abdul-Salam, V.; McKinnon, T.; Duluc, L.; Pepke-Zaba, J.; Southwood, M.; Ainscough, A.J.; Hadinnapola, C.; Wilkins, M.R.; Toshner, M.; et al. Neutrophil Extracellular Traps Promote Angiogenesis: Evidence From Vascular Pathology in Pulmonary Hypertension. Arterioscler. Thromb. Vasc. Biol. 2016, 36, 2078-2087. [CrossRef] 
40. Fang, L.; Karakiulakis, G.; Roth, M. Are patients with hypertension and diabetes mellitus at increased risk for COVID-19 infection? Lancet. Respir. Med. 2020, 8, e21. [CrossRef]

41. Zheng, K.I.; Gao, F.; Wang, X.B.; Sun, Q.F.; Pan, K.H.; Wang, T.Y.; Ma, H.L.; Liu, W.Y.; George, J.; Zheng, M.H. Obesity as a risk factor for greater severity of COVID-19 in patients with metabolic associated fatty liver disease. Metabolism 2020, 154244. [CrossRef] [PubMed]

42. Wu, Z.; McGoogan, J.M. Characteristics of and Important Lessons From the Coronavirus Disease 2019 (COVID-19) Outbreak in China: Summary of a Report of 72314 Cases From the Chinese Center for Disease Control and Prevention. Jama 2020. [CrossRef] [PubMed]

43. Wong, S.L.; Demers, M.; Martinod, K.; Gallant, M.; Wang, Y.; Goldfine, A.B.; Kahn, C.R.; Wagner, D.D. Diabetes primes neutrophils to undergo NETosis, which impairs wound healing. Nat. Med. 2015, 21, 815-819. [CrossRef]

44. Salem, E.S.; Grobe, N.; Elased, K.M. Insulin treatment attenuates renal ADAM17 and ACE2 shedding in diabetic Akita mice. Am. J. Physiol. Renal. Physiol. 2014, 306, F629-F639. [CrossRef]

45. Reynolds, H.R.; Adhikari, S.; Pulgarin, C.; Troxel, A.B.; Iturrate, E.; Johnson, S.B.; Hausvater, A.; Newman, J.D.; Berger, J.S.; Bangalore, S.; et al. Renin-Angiotensin-Aldosterone System Inhibitors and Risk of Covid-19. N. Engl. J. Med. 2020. [CrossRef]

46. Kraakman, M.J.; Lee, M.K.; Al-Sharea, A.; Dragoljevic, D.; Barrett, T.J.; Montenont, E.; Basu, D.; Heywood, S.; Kammoun, H.L.; Flynn, M.; et al. Neutrophil-derived S100 calcium-binding proteins A8/A9 promote reticulated thrombocytosis and atherogenesis in diabetes. J. Clin. Investig. 2017, 127, 2133-2147. [CrossRef]

47. Nicholas, D.A.; Proctor, E.A.; Agrawal, M.; Belkina, A.C.; Van Nostrand, S.C.; Panneerseelan-Bharath, L.; Jones, A.R.t.; Raval, F.; Ip, B.C.; Zhu, M.; et al. Fatty Acid Metabolites Combine with Reduced $\beta$ Oxidation to Activate Th17 Inflammation in Human Type 2 Diabetes. Cell Metab. 2019, 30, 447-461. [CrossRef]

48. Wu, D.; Yang, X.O. TH17 responses in cytokine storm of COVID-19: An emerging target of JAK2 inhibitor Fedratinib. J. Microbiol. Immunol. Infect. 2020. [CrossRef]

49. Guo, T.; Fan, Y.; Chen, M.; Wu, X.; Zhang, L.; He, T.; Wang, H.; Wan, J.; Wang, X.; Lu, Z. Cardiovascular Implications of Fatal Outcomes of Patients With Coronavirus Disease 2019 (COVID-19). JAMA Cardiol. 2020. [CrossRef]

50. Chapman, A.R.; Bularga, A.; Mills, N.L. High-Sensitivity Cardiac Troponin Can Be an Ally in the Fight Against COVID-19. Circulation 2020, 141, 1733-1735. [CrossRef]

51. Yadav, V.; Chi, L.; Zhao, R.; Tourdot, B.E.; Yalavarthi, S.; Jacobs, B.N.; Banka, A.; Liao, H.; Koonse, S.; Anyanwu, A.C.; et al. Ectonucleotidase tri(di)phosphohydrolase-1 (ENTPD-1) disrupts inflammasome/ interleukin 1beta-driven venous thrombosis. J. Clin. Investig. 2019, 129, 2872-2877. [CrossRef]

52. Liberale, L.; Holy, E.W.; Akhmedov, A.; Bonetti, N.R.; Nietlispach, F.; Matter, C.M.; Mach, F.; Montecucco, F.; Beer, J.H.; Paneni, F.; et al. Interleukin-1beta Mediates Arterial Thrombus Formation via NET-Associated Tissue Factor. J. Clin. Med. 2019, 8, 2072. [CrossRef]

53. Mansuy-Aubert, V.; Zhou, Q.L.; Xie, X.; Gong, Z.; Huang, J.Y.; Khan, A.R.; Aubert, G.; Candelaria, K.; Thomas, S.; Shin, D.J.; et al. Imbalance between neutrophil elastase and its inhibitor $\alpha 1$-antitrypsin in obesity alters insulin sensitivity, inflammation, and energy expenditure. Cell Metab. 2013, 17, 534-548. [CrossRef]

(C) 2020 by the authors. Licensee MDPI, Basel, Switzerland. This article is an open access article distributed under the terms and conditions of the Creative Commons Attribution (CC BY) license (http://creativecommons.org/licenses/by/4.0/). 